\title{
Article \\ Hysteresis Response Loops in Stationary Vibrator Regimes for Elastomeric Insulators
}

\author{
Polidor Bratu ${ }^{1,2, * \mathbb{C}}$, Cornelia Dobrescu ${ }^{3}$ and Nicu Drăgan ${ }^{4}$ \\ 1 Mechanical Engineering Section, Romanian Academy of Technical Sciences, 030167 Bucharest, Romania \\ 2 Institute of Solid Mechanics of the Romanian Academy, 021652 Bucharest, Romania \\ INCD URBAN INCERC, 021652 Bucharest, Romania; cornelia.dobrescu@incd.ro \\ 4 Faculty of Engineering and Agronomy, “Dunărea de Jos” University of Galați, 800008 Galați, Romania; \\ nicu.dragan@ugal.ro \\ * Correspondence: icecon@icecon.ro; Tel.: +40-21-202-55-00
}

check for

updates

Citation: Bratu, P.; Dobrescu, C.; Drăgan, N. Hysteresis Response Loops in Stationary Vibrator Regimes for Elastomeric Insulators. Symmetry 2022, 14, 246. https://doi.org/ $10.3390 /$ sym 14020246

Academic Editors: Juan Luis García Guirao and Sergei D. Odintsov

Received: 15 October 2021 Accepted: 4 January 2022

Published: 27 January 2022

Publisher's Note: MDPI stays neutral with regard to jurisdictional claims in published maps and institutional affiliations.

Copyright: (c) 2022 by the authors. Licensee MDPI, Basel, Switzerland. This article is an open access article distributed under the terms and conditions of the Creative Commons Attribution (CC BY) license (https:// creativecommons.org/licenses/by/ $4.0 /)$.

Abstract: In order to raise the hysteresis loops in stationary dynamic regimes in the case of elastomeric insulators, specialized dynamic stands are used that may obtain both the necessary harmonic excitation by force as well as the modification of the angular arrangement discreetly variable from zero to 90 degrees. In this context, for the evaluation of the elastomeric insulators, a dynamic stand with an inertial vibrator was used, the frequency of which can be changed by continuous adjustment within the range of values from $2 \mathrm{~Hz}$ to $60 \mathrm{~Hz}$. Forces and displacements can be measured with the appropriate sensors, and based on the recording of signals, the characteristics of rigidity, damping and the raise of hysteresis loops could be determined for three significant dynamic regimes: anteresonance and post-resonance. Research on the dynamic stand, patented in Romania, has highlighted the fact that the parametric evaluation can be performed based on the lifting of the hysteretic loops in stationary harmonic regimes. Additionally, there are two situations specifically mentioned, one in which the significant inertial effect for the $F-x$ loops leads to their positioning in quadrants II and IV, and the case of $Q-x$ loops, where the inertial effect does not exist, and their positioning is only in quadrants I and III. From the analysis of the two cases, the most advantageous evaluation method for the test can be chosen. This article provides the calculation relationships established for the dynamic model with linear viscoelastic behaviour. The requirements of Voight-Kelvin modeling with a single degree of freedom is fully justified and ensured by the conditions of geometric and mass symmetry in the construction of the stand. The verification of the numerical results with the experimental ones was performed with the hysteresis loops corresponding to the previously defined three significant dynamic regimes, as well as according to the three positions of the elastomeric insulators for compression, compression-shear and shear.

Keywords: elastomeric insulator; anti-vibrator; resonance; hysteresis loop; dissipated energy

\section{Introduction}

The analysis of the dynamic response for distinct positions of placing the elastomeric insulators showed that, depending on the dynamic ante-resonance or post-resonance regime, the dissipated energy, the force transmitted to the foundation, and the rigidity and damping characteristics are defining parameters in designing and/or optimizing an antivibration system [1-6]. Thus, in Romania, at ICECON Bucharest, dynamic test stands were developed for elastomeric insulators used in industry and construction [7].

The experiments on elastomeric insulators, either made in Romania or imported from companies in Europe and the USA, were performed on a dynamic stand patented in Romania and owned by ICECON Bucharest. In principle, the dynamic stand consists of three vertical columns and an inertial vibrator located at the top.

Each column consists of a two semi-cylindrical bodies system with central seats where the elastomer insulator is mounted. In the mounted system, a circular group with radial 
holes is formed so that it may be positioned at various angles, with a 15-degree angular pace. Thus, the angular position of placing the elastomeric insulator is defined by the angle $\alpha$ formed by the direction of the vertical perturbator force and the compression axis of the elastomeric device. Experimental tests were performed for all positions indexed with the $15^{\circ}$ step, by performing simple or combined requirements such as: compression at $\alpha=0^{\circ}$, compression + shear at $\alpha>0$ and shear at $\alpha=90^{\circ}$ [8-13].

On the analyzed dynamic stand, 628 tests were performed for elasatomeric antivibration devices that were analyzed and certified in the period 2015-2020, the manufacturers being from Romania, Italy, France, Austria and Spain. The experimental results were statistically processed, taking into account the uncertainty of the measurements $[14,15]$.

\section{Test Stand Constructive Scheme}

Figure 1 presents the construction solution of the stand with three test groups arranged at $120^{\circ}$ so that the vertical excitation force may be applied equally to each elastomeric insulator. The following notations were used in Figure 1: 1-variable speed drive electric engine; 2-unidirectional vibrator; 3-adjustment and fixing support; 4-upper beam; 5 -force transducer $T_{f} ; 6$ - semi-circular clamping device; 7-elastomeric insulator; 8-displacement transducer $T_{x} ; 9$-force transducer $T_{q} ; 10$-fixed base (frame) [16-20].

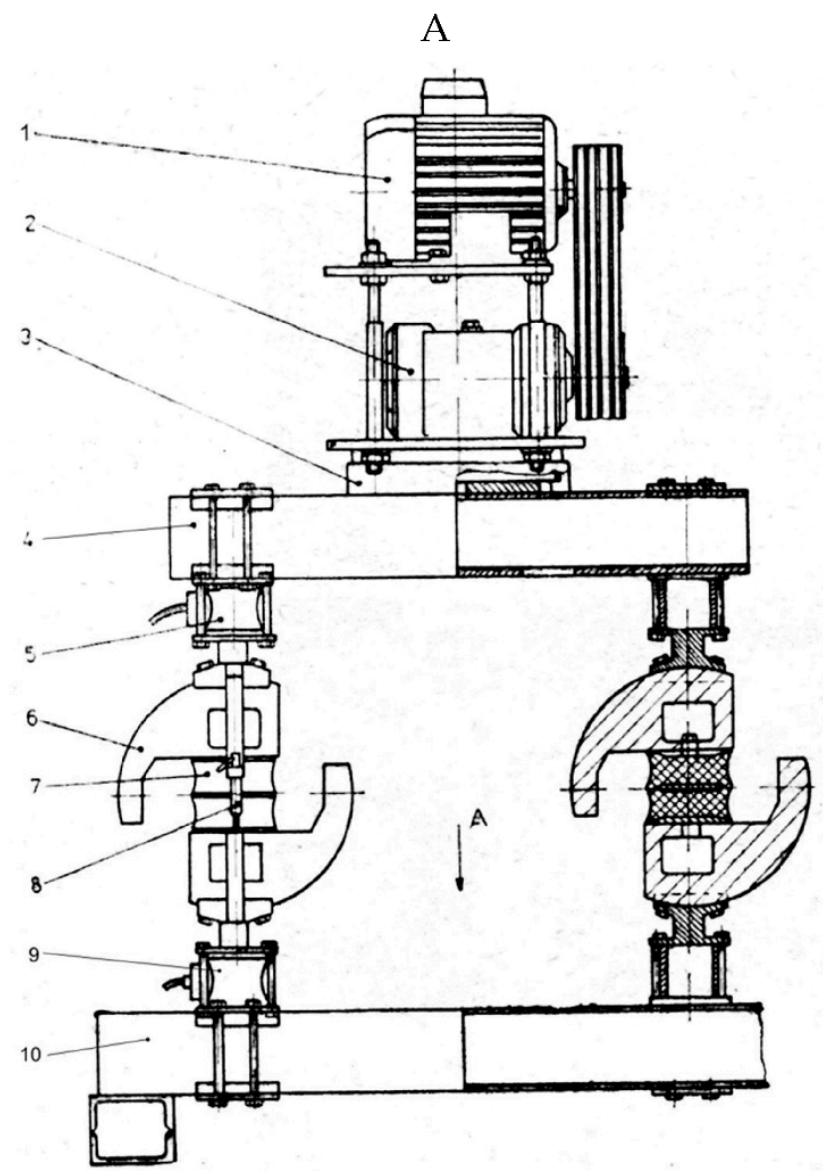

Seen from A

Figure 1. Dynamic stand scheme.

The inertial vibrator generates a vertical force, harmonic with parallel and symmetrical action direction in relation to the three elastomeric insulators connected in parallel. Transducer $T_{f}$ measures the incident force on the elastomeric insulator, transducer $T_{q}$ measures the emergent force, or the force transmitted at the base and transducer $T_{x}$ measures the instantaneous displacement $x=x(t)$ or the vertical deformation of the deformable assembly. Each column has its own system of transducers $T_{x}$ si $T_{f}$. 
The principle schematization of the stand in constructive solution is presented in Figure 2 where the following notations were used: 1 -unidirectional vibrator mounted on upper structure; 2-force transducer (tensometric dose) input; 3-upper semi-circular guiding device and radial positional indexing; 4-upper device for holding the elastomeric insulator; 5-elastomeric insulator; 6-lower device for holding the elastomeric insulator; 7-lower semi-circular device for guiding and radial positional indexing; 8-force transducer (tensometric dose) output; 9-fixed base.

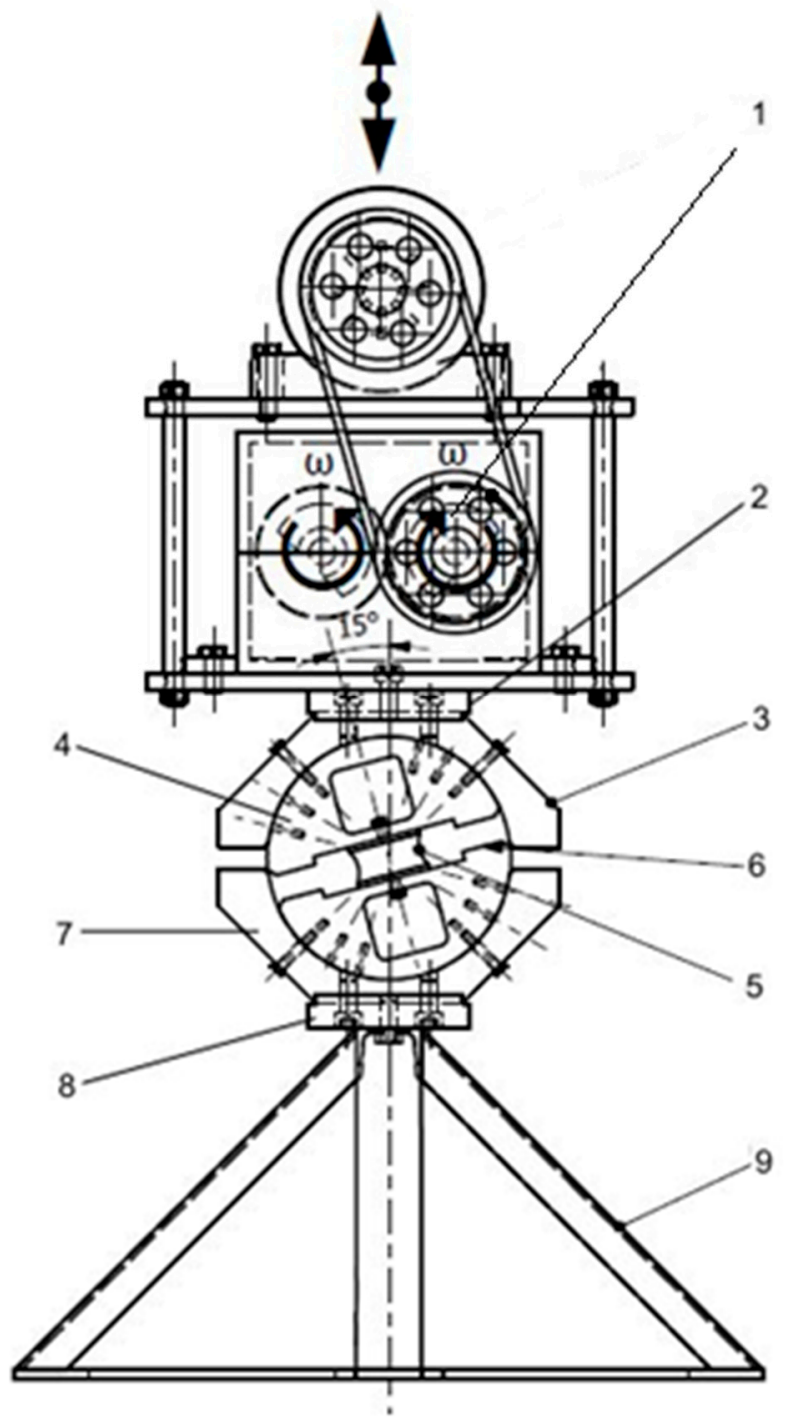

Figure 2. Principle scheme for one test group.

It is shown that the force transducer 5 and the displacement transducer 7 in Figure 1, are mounted and maintained in the initial mechanical state, regardless of any modifications of the angular position of group 6. This makes the initial calibration of the transducers uninfluenced by the subsequent states of the dynamic tests.

Figure 3 presents the schematic of the linear dynamic model, where $x=x(t)$ is the instantaneous displacement; $F=F(t)$ harmonic excitation force; $m$-mass of the mobile assembly; $Q=Q(t)$-the force transmitted to the base; $k$-stiffness of the insulator in the vertical direction; $c$ - viscous damping; $T_{f}$-the incident force transducer which measures force $F(t) ; T_{q}$ - the displacement transducer that measures the instantaneous displacement $x=x(t)$. 


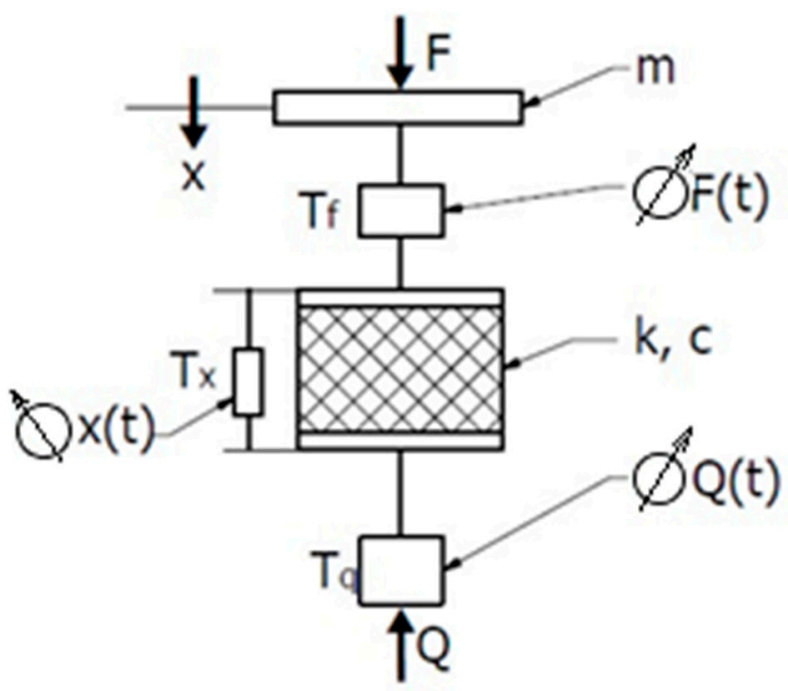

Figure 3. Schematization of the position of the force transducers $T_{f}, T_{q}$ and of the displacement transducer $T_{x}$.

The significant positions of the elastomeric insulator are presented in Figure 4 where the axes of the fixed system are $O x$ and $O_{y}$, and the moving axes $O_{c}$, for compression, and $O_{f}$, for shear, are connected to the elastomeric device. The three distinct positions are highlighted by the seating angle $\alpha$. Thus, for compression $\alpha=0$, compression-shear $\alpha>0$ and $\alpha<90$, and for shear $\alpha=90^{\circ}[21,22]$.
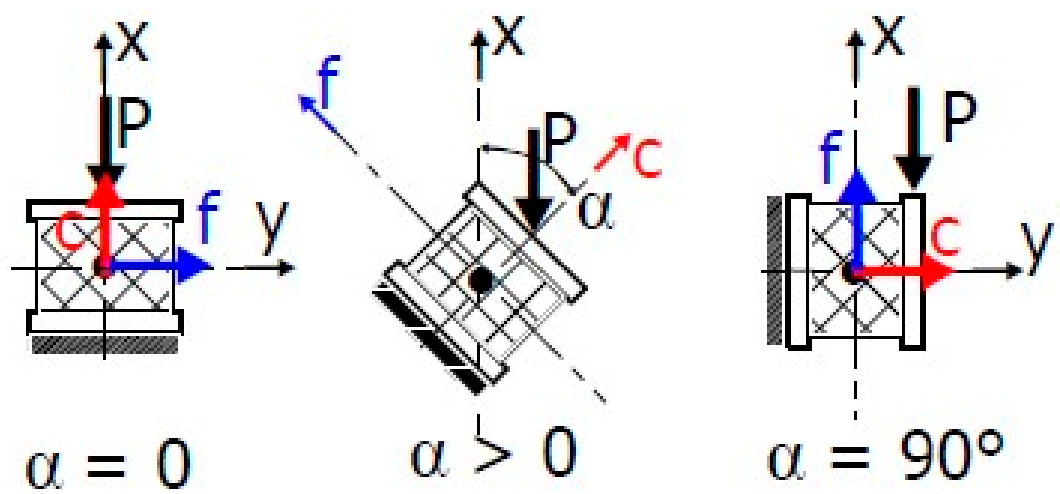

Figure 4. Stage significant positions.

\section{Evaluation of Dissipated Energy}

Highlighting the modality of variation of the dissipated energy, in some well specified cases, is a criterion for optimizing the dynamic system based on the stationary harmonic regime and of the linear viscoelastic characteristics of the elastomeric insulators (stiffness $k$ and viscous damping $c$ ) [22]. In this case, for a dynamic regime with relative pulsation $\Omega=\frac{\omega}{\omega_{n}}$, where $\omega$ is the excitation pulsation and $\omega_{n}$ is its own pulsation, the dissipated energy $W_{d}$ may be expressed as:

$$
W_{d}(\Omega, \zeta)=2 \pi\left(\frac{m_{0} r}{m}\right)^{2} k \zeta \frac{\Omega^{5}}{\left(1-\Omega^{2}\right)^{2}+(2 \zeta \Omega)^{2}}
$$

where $\zeta$ is damping rate or the fraction of the critical damping (where $\zeta=c / c_{r}$, where $c$-effective viscous damping, and $c_{r}$-critical viscous damping). Usually, $\zeta$ is under the value of 0.7 ;

$k$-system stiffness, $\mathrm{N} / \mathrm{m}$; 
$m_{0} r$-static moment of the exciter with eccentric bodies in rotation motion, $\mathrm{kg} \cdot \mathrm{m}$;

$m$-mobile mass of the stand, $\mathrm{kg}$;

The maximum dissipated energy in the ante-resonance regime $W_{d, a}^{\max }$ corresponds to a fraction of the critical damping $\zeta_{a}^{0}=\frac{1-\Omega_{a}^{2}}{2 \Omega_{a}}$, so it may be written as:

$$
W_{d, a}^{m a x}=2 \pi\left(\frac{m_{0} r}{m}\right)^{2} k \frac{\Omega_{a}^{4}}{4\left(1-\Omega_{a}^{2}\right)}
$$

where $\Omega_{a}<1$ is the ante-resonance relative pulsation.

The maximum dissipated energy in the post-resonance regime $W_{d, p}^{\max }$ corresponds to pulsation $\Omega_{p}>1$ and to the fraction of the critical damping $\zeta_{p}^{0}=\frac{\Omega_{p}^{2}-1}{2 \Omega_{p}}$, so that we have

$$
W_{d, p}^{\max }=2 \pi\left(\frac{m_{0} r}{m}\right)^{2} k \frac{\Omega_{p}^{4}}{4\left(\Omega_{p}^{2}-1\right)}
$$

The dissipated energy in the resonance regime $W_{d}^{r e z}$ corresponds to pulsation $\Omega=1$ and to the fraction of the critical damping $\zeta_{n}=\frac{c}{2 m \omega_{n}}$, so that we have

$$
W_{d}^{r e z}=2 \pi\left(\frac{m_{0} r}{m}\right)^{2} k \frac{1}{4 \zeta_{n}}
$$

From Relations (2), (4) then from Relations (3) and (4), it emerges the following correlations

$$
\begin{aligned}
W_{d, a}^{\max } & =W_{d}^{r e z} \frac{\Omega_{a}^{4}}{1-\Omega_{a}^{2}} \zeta_{n} \\
W_{d, p}^{\max } & =W_{d}^{r e z} \frac{\Omega_{p}^{4}}{1-\Omega_{p}^{2}} \zeta_{n}
\end{aligned}
$$

The correlation between $W_{d, a}^{\max }$ and $W_{d, p}^{\max }$ emerges from Relations (5) and (6) as

$$
\frac{W_{d, p}^{\max }}{W_{d, a}^{\max }}=\left(\frac{\Omega_{a}}{\mathrm{a}}\right)^{2} \frac{1-\Omega_{a}^{2}}{\Omega_{p}^{2}-1}
$$

\subsection{Dissipated Energy as a Function of Damping}

For the current variable $\zeta$ with $\Omega \neq 1$ mentioned at constant value, we have the following situations, that is:

(a) ante-resonance with $\Omega_{a}<1$ for which we have

$$
W_{d, a}^{c i c l u}(\zeta)=2 \pi\left(\frac{m_{0} r}{m}\right)^{2} k \zeta \frac{\Omega_{a}^{5}}{\left(1-\Omega^{2}\right)^{2}+(2 \zeta \Omega)^{2}}
$$

with graphical representation in Figure $5[23,24]$. 


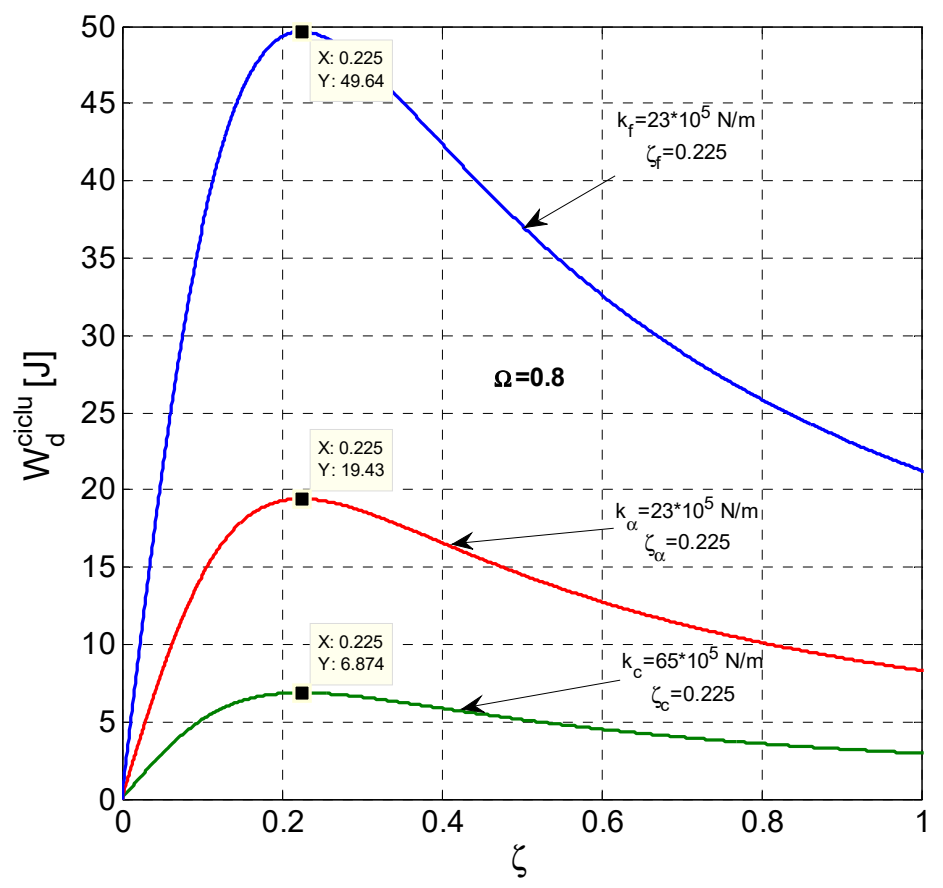

Figure 5. Variation of dissipated energy per cycle, in ante-resonance regime, depending on the damping ratio $\zeta$ and stiffness $k$ for $\Omega=0.8$.

(b) Post-resonance with $\Omega_{p}>1$ for which it is valid the relation

$$
W_{d, p}^{c i c l u}(\zeta)=2 \pi\left(\frac{m_{0} r}{m}\right)^{2} k \zeta \frac{\Omega_{p}^{5}}{\left(1-\Omega^{2}\right)^{2}+(2 \zeta \Omega)^{2}}
$$

with graphical representation in Figure 6 [23,24].

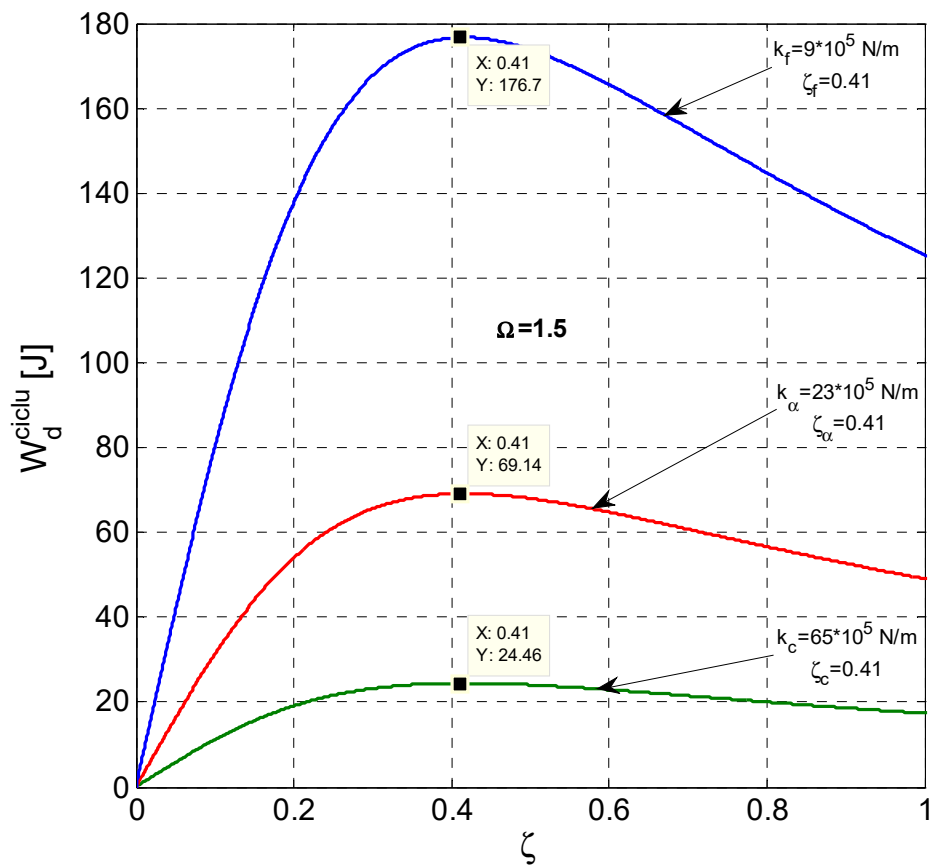

Figure 6. Variation of dissipated energy per cycle, in post-resonance regime, depending on the damping ratio $\zeta$ and stiffness $k$ for $\Omega=1.5$. 
The three curves in Figures 5 and 6 correspond to the cases in which the elastomeric anti-vibration devices, required for compression with $k_{c}$, compression-shear $k_{\alpha}$ and shear $k_{f}$ are characteristic of the ante-resonance regime $\Omega_{a}=0.8, \zeta_{a}^{0}=0.225$ and, respectively, of the post-resonance regime $\Omega_{p}=1.5, \zeta_{p}^{0}=0.41[23,24]$.

\subsection{Dissipated Energy as a Function of Relative Pulsation}

The energy dissipated per cycle $W_{d}{ }^{c i c l u}(\Omega)$ depending on the relative excitation pulsation $\Omega=\frac{\omega}{\omega_{n}}$ for the given values of stiffness $k$ and the fraction of the critical damping $\zeta$ is given by relation, with the parameter order $i$, so

$$
W_{d}^{c i c l u}(\Omega)=2 \pi\left(\frac{m_{0} r}{m}\right)^{2} k_{i} \zeta_{i} \frac{\Omega^{5}}{\left(1-\Omega^{2}\right)^{2}+\left(2 \zeta_{i} \Omega\right)^{2}}=E_{i}
$$

where $i=1,2, \ldots, n$ represents the index of the parametric order $k_{i}, \zeta_{i}$ which describes a curve from the curve family with current variable $\Omega[23,24]$. of $\Omega$.

Figure 7 shows the curve family with discrete values $k_{i}, \zeta_{i}$ and the continuous variation

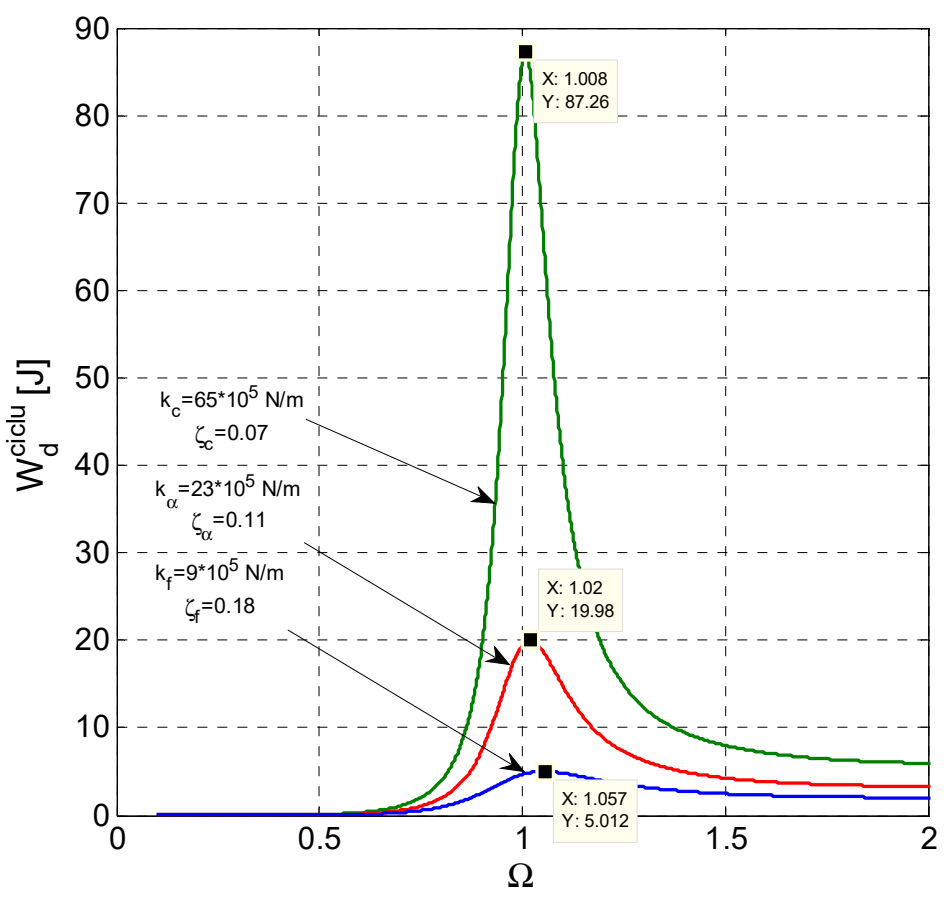

Figure 7. Variation of dissipated energy per cycle, as a function of relative pulsation $\Omega$ and discrete variation of parameters $k$ and $\zeta$.

The relative pulsation $\Omega_{i}$ can also be written as

$$
\Omega_{i}=\omega \sqrt{\frac{m}{k_{i}}}
$$

where, $k_{i}$ is the stiffness for $i=c, \alpha, f$, for the three situations corresponding to angle $\alpha=0^{\circ}$, $\alpha=60^{\circ}, \alpha=90^{\circ}$, respectively, compression, compression-shear and shear.

As $k_{c}>k_{\alpha}>k_{f}$, it emerges that the relative pulsations are in order $\Omega_{\mathcal{c}}<\Omega_{\alpha}<\Omega_{f}$ as shown in Figure 7.

The raised curves in Figures 5-7 are obtained numerically, and the marked values are obtained experimentally in the stationary dynamic regime regulated and controlled especially for this purpose. The deviations of the experimental values in relation to those obtained numerically fall within the range $-3-5 \%$. 


\section{Hysteretic Loops}

For the viscoelastic linear dynamic system, the hysteretic loops of elliptic shape can be represented for the dynamic excitation force $F(t)$ in relation to deformation $x=x(t)$ in coordinates $F-x$, as well as for the transmitted dynamic force $Q=Q(t)$ depending on deformation $x=x(t)$ in coordinates $Q-x$.

(a) Hysteretic loops in F- $x$ coordinates

The equation of the elliptical hysteretic loops in the coordinate system $F-x$ is given by the relation parameterized by $k$ and $\zeta$ discrete variable and $x$ continuous variable, so that $x \in[-A,+A]$, the demonstration is given in the following papers $[24,25]$.

Thus, we have

$$
F(x, \Omega)=k\left[\left(1-\Omega^{2}\right) x \pm 2 \zeta \Omega \sqrt{A^{2}-x^{2}}\right]
$$

where $A=A(\Omega)$ is the amplitude of instantaneous displacement (deformation) $x=x(t)$.

$$
A=A(\Omega)=\frac{m_{0} r}{m} \Omega^{2} \frac{1}{\sqrt{\left(1-\Omega^{2}\right)^{2}+\left(2 \zeta_{i} \Omega\right)^{2}}}
$$

Figure 8 for $\Omega_{a}=0.8$ in the ante-resonance regime presents the family of elliptical loops for the three significant cases of the viscoelastic system $\alpha_{c}=0^{\circ}, \alpha=60^{\circ}$ and $\alpha_{f}=90^{\circ}$ that is in situation $k_{c}, \zeta_{c}, k_{\alpha}, \zeta_{\alpha}$ and $k_{f}, \zeta_{f}$. It is specified that all ellipses are inclined in quadrants I and III $[23,24]$.

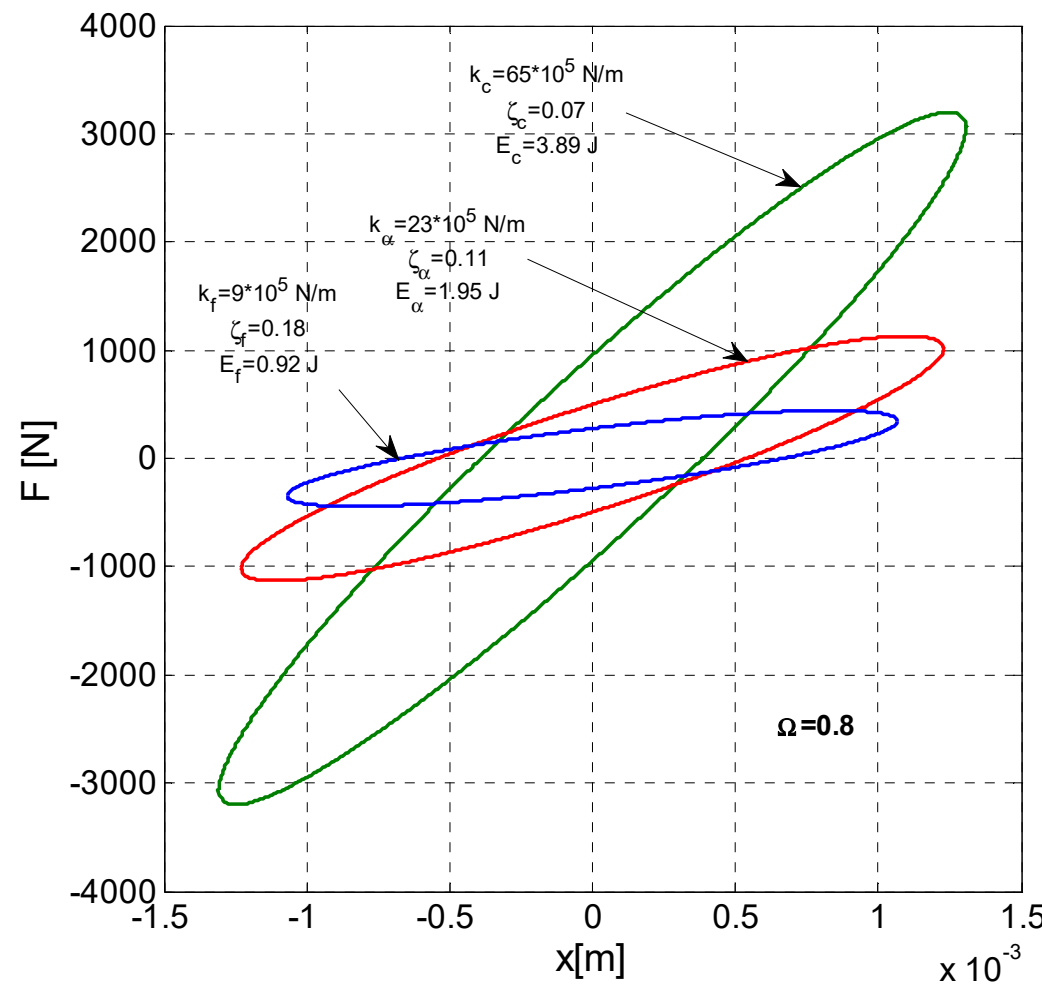

Figure 8. Hysteretic loops $F-x$ in ante-resonance regime for $\Omega=0.8$.

Figure 9 for $\Omega_{p}=1.5$ in the post-resonance regime presents the family of elliptical loops for the three significant cases, with the specification that all ellipses are inclined in quadrant II and IV as effect of the influence of the resonance regime [23-25]. 


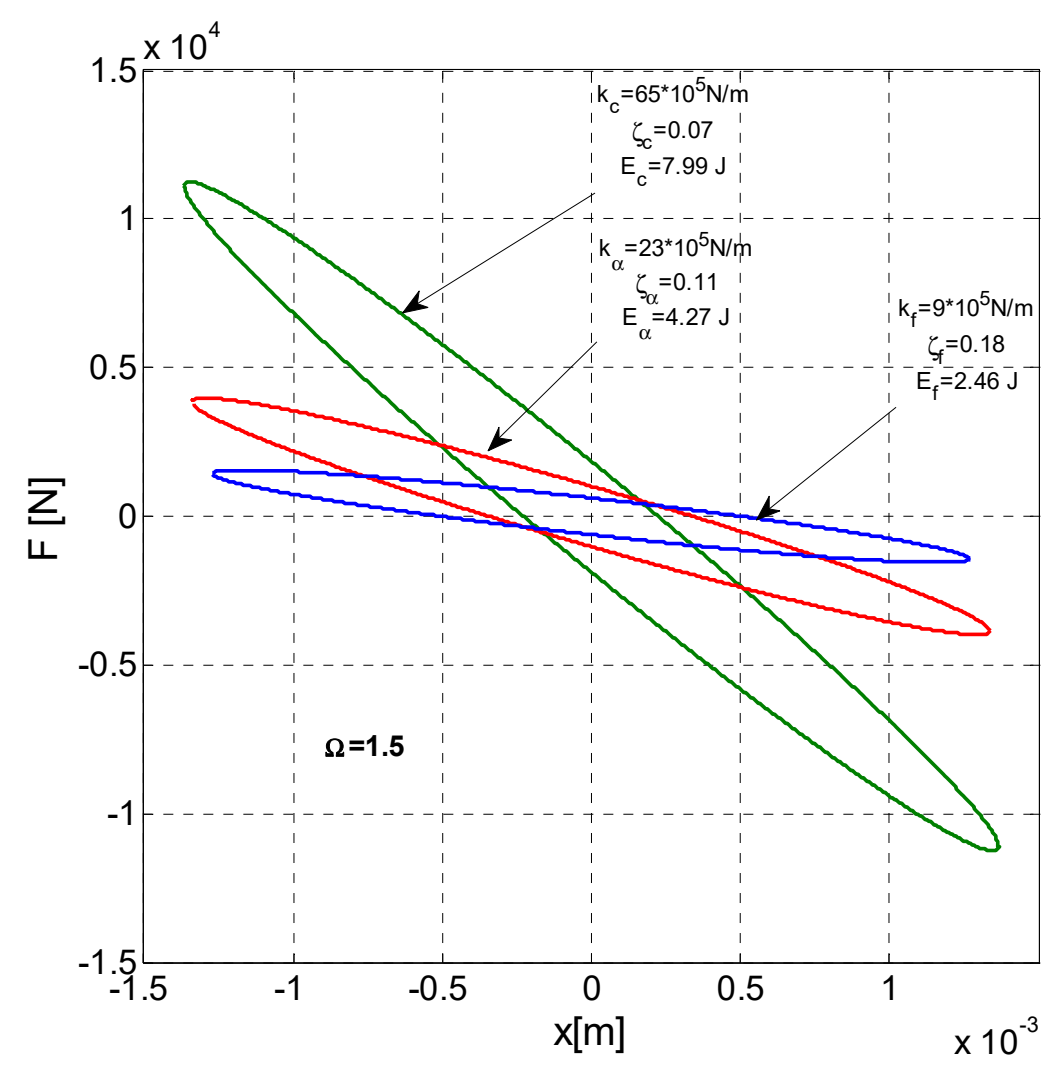

Figure 9. Hysteretic loops $F-x$ in pot-resonance regime for $\Omega=1.5$.

Figure 10 shows the elliptical hysteretic loops in resonance mode for the three significant cases.

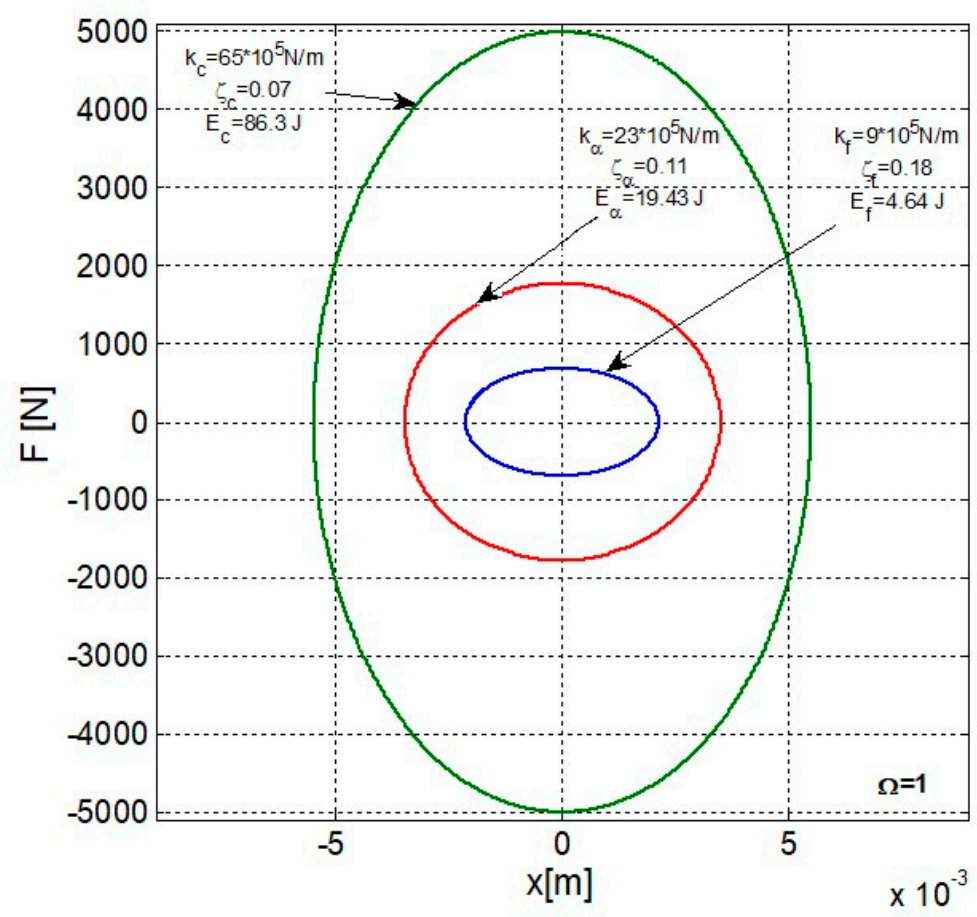

Figure 10. Centered elliptical hysteretic loops $F-x$ in resonance regime for $\Omega=1 . \alpha_{c}=0, \alpha=60^{\circ}$ and $\alpha_{\mathrm{f}}=90^{\circ}$. 
It is found that the energy dissipated at resonance $E_{c}, E_{\alpha}$ and $E_{f}$ with the values in Figure 10 coincides with the corresponding values in Figure 7.

Figures 8 and 9 show the significant inertial effect in post-resonance with hysteretic loops in quadrants I and IV compared to the reduced inertial effect for pre-resonance with hysteretic loops found only in quadrants I and III.

(b) Hysteretic loops in $Q-x$ coordinates

The equation of the elliptical hysteretic loops in coordinates $Q-x$ is given by the equation parameterized by $k$ and $\zeta$ discrete variables and by the continuous variable $x \in[-A,+A]$. In this case we have

$$
Q(x, \Omega)=k\left[x \pm 2 \zeta \Omega \sqrt{A^{2}-x^{2}}\right]
$$

where $\Omega$ is $\Omega_{a}<1, \Omega_{p}>1$ and $\Omega=1$ [23-25].

In Figure 11 at $\Omega_{a}=0.8$ in ante-resonance, for the three significant values and $k_{c}, \zeta_{c}$, $k_{\alpha}, \zeta_{\alpha}$ and $k_{f}, \zeta_{f}$ it is presented as the family of elliptical loops, all inclined in quadrants I and III.

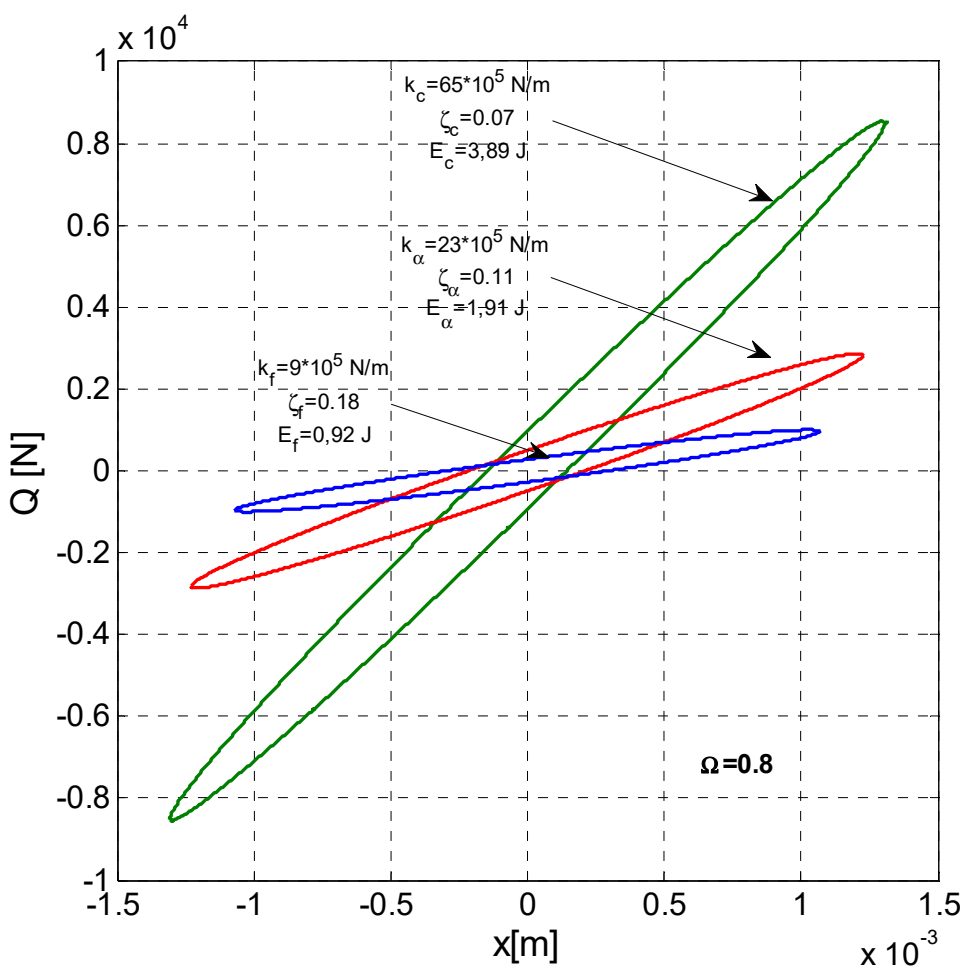

Figure 11. Hysteretic loops $Q-x$ in ante-resonance regime for $\Omega=0.8$.

Figure 12 at $\Omega_{p}=1.5$ in post-resonance, for the three sets of significant values $k_{c}, \zeta_{c}$, $k_{\alpha}, \zeta_{\alpha}$ and $k_{f}, \zeta_{f}$ there are presented the hysteretic loops in quadrants I and III. 


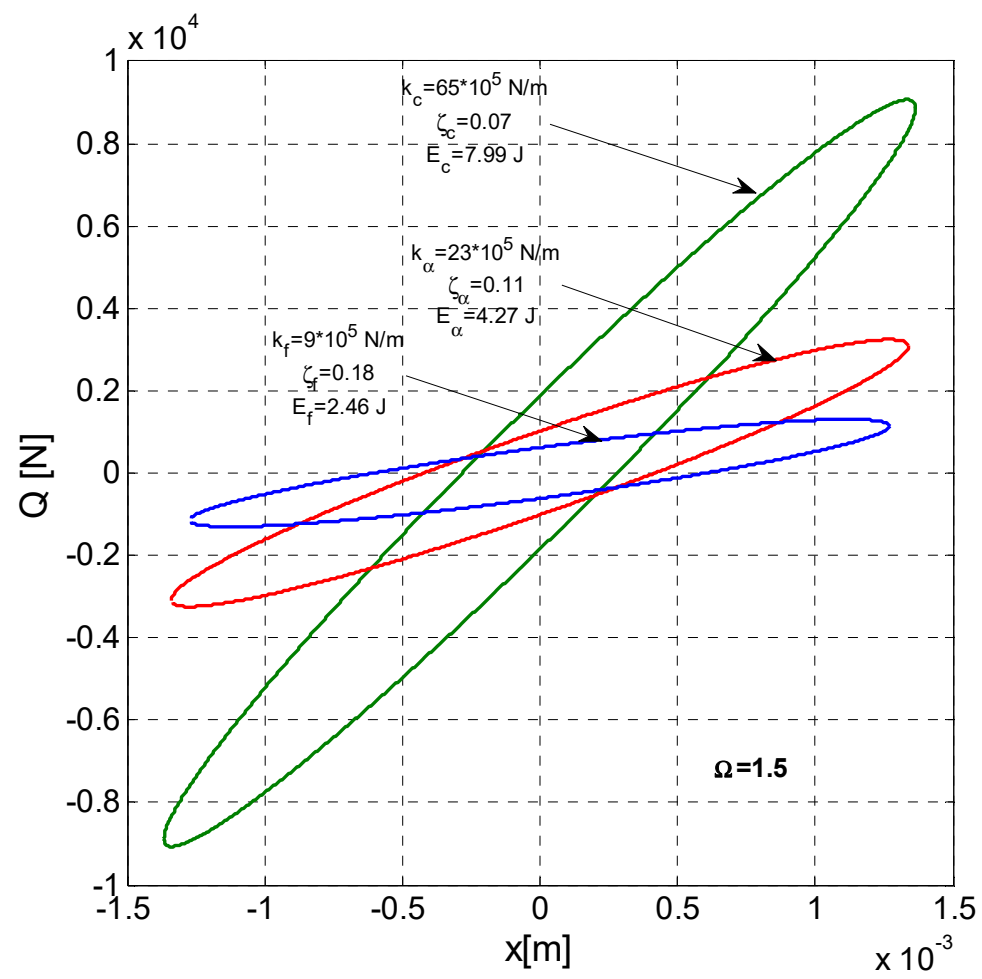

Figure 12. Hysteretic loops $Q-x$ in post-resonance regime for $\Omega=1.5$.

Figure 13 for $\Omega=1$ at resonance presents the hysteretic loops for the three sets of significant data. It is found that the areas of the elliptical hysteretic loops are the same as the ones in Figure 10 in the F- $x$ system at resonance.

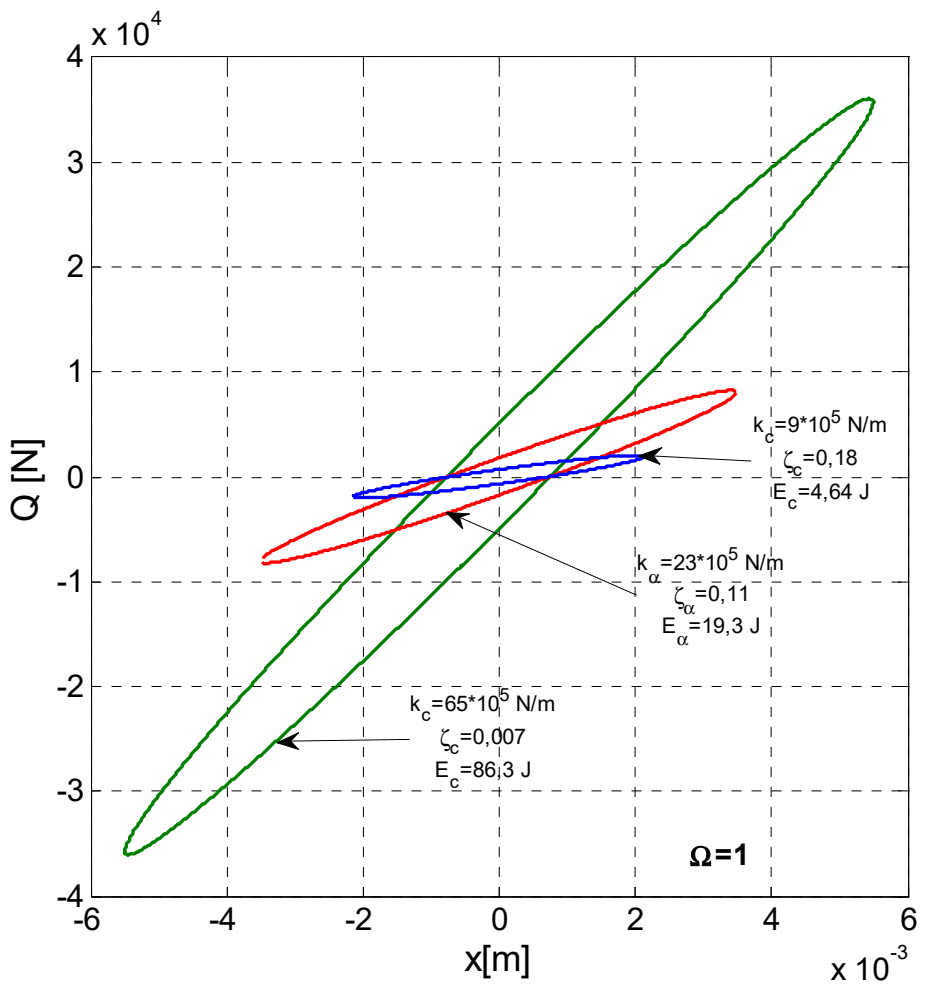

Figure 13. Hysteretic loops $Q-x$ in resonance regime for $\Omega=1$. 


\section{Conclusions}

Based on the analysis of the analytical relations established both for the dissipated energy as well as for the representation of the hysteretic loops specific to the linear viscoelastic system that models a dynamic stand for elastomeric anti-vibration devices, the following conclusions can be drawn:

(a) The analytical expression of the dissipative energy offers the possibility of evaluation for two significant cases, namely:

- The variation of the dissipated energy depending on the discrete change of the damping for the three dynamic regimes: ante-resonance, post-resonance and resonance;

- The variation of the dissipated energy depending on the variation of $\Omega$ for discrete variable sets of values of $k$ and $\zeta$;

(b) The representation of the elliptical hysteretic loops in the $F-x$ coordinate system for the three cases of the dynamic regimes, namely: ante-resonance, post-resonance and resonance. It was found that in post-resonance the inclination of the axes of the ellipses towards the ante-resonance regime changes due to the inertial effect of the mass, and in resonance, the ellipses are symmetrically centered in relation to the $F-x$ axis system.

(c) The elliptical hysteretic loops in the $Q-x$ system are inclined only in quadrants I and III, regardless of the dynamic regime.

(d) The areas of the ellipses represent the dissipated energy. The numerical results were verified by experimental lifting of hysteretic loops on the dynamic stand.

The experimental values were verified in accordance with those numerically determined by hysteretic loops with deviations of $-3-5 \%$.

Author Contributions: Conceptualization, P.B.; methodology, P.B.; software, N.D.; validation, P.B., C.D., N.D.; formal analysis, C.D.; investigation, C.D.; data curation, N.D.; writing—original draft preparation, P.B. All authors have read and agreed to the published version of the manuscript.

Funding: This research received no external funding.

Institutional Review Board Statement: Not applicable.

Informed Consent Statement: Not applicable.

Data Availability Statement: Not applicable.

Conflicts of Interest: The authors declare no conflict of interest.

\section{References}

1. Dobrescu, C. The Rheological Behaviour of Stabilized Bioactive Soils during the Vibration Compaction Process for Road Structures. In Proceedings of the 22th International Congress on Sound and Vibration, Florence, Italy, 12-16 July 2015.

2. Chen, B.J.; Lin, S.B.; Tsai, C.S. Theoretical and Experimental Study of High Damping Rubber Bearings. In Proceedings of the Seismic Engineering 2001, the 2000 ASME Pressure Vessels and Piping Conference, Seattle, WA, USA, 23-27 July 2000; Russel, G., Ed.; Volume 2.

3. Kelly, J.; Konstantinidis, A.D. Mechanics of Rubber Bearings for Seismic and Vibration Isolation; John Wiley \& Sons, Ltd.: Chichester, UK, 2011.

4. Delfosse, C.G. Étude des vibrations linéaires d'un systeme mecanique complexe par méthode des mates normaux. Ann. L'ITBTP 1976, 336, 122-136.

5. Giacchetti, R. Fondamente di Dinamica Delle Strutture e di Ingineria Sismica; EPC Libri: Roma, Italy, 2004.

6. Kramer, H. Angewandte Baudynamic; Ernst \& Sohn: Berlin, Germany, 2007.

7. Bratu, P. Rheological model of the neopren elements used for base isolation against seismic actions. Mater. Plast. 2009, 46, $288-294$.

8. $\quad$ Rao, M. Mechanical Vibrations; Addison-Wesley Pub. Co.: Boston, MA, USA, 1995.

9. Sireteanu, T.; Giuclea, M.; Mitu, A.M. An analitical approach for approximation of experimental hysteretic by Bouc.-Wen model. Proc. Rom. Acad. Ser. A 2009, 10, 43-54.

10. Le Tallec, P. Introduction à la Dynamique des Structures; Cépaduès: Toulouse, France, 2000.

11. Trigili, G. Introduzione alla Dinamica delle Strutture e Spettri di Progeto; Dario, F., Ed.; Laccorio: Palermo, Italy, 2010.

12. Rades, M. Mechanical Vibrationes; Ed. Printech: București, Romania, 2006. 
13. Stanescu, N.D. Vibrations of a shell with clearances, neo-Hookean stiffness, and harmonic excitations. Rom. J. Acoust. Vib. 2016, 13, 104-111.

14. Vasile, O. Active vibration control for viscoelastic damping systems under the action of inertial forces. Rom. J. Acoust. Vib. 2017, $14,54-58$.

15. Inman, D. Vibration with Control; John Wiley \& Sons Ltd.: London, UK, 2007.

16. Bratu, P. Stand for Measuring Perturbing Force. Patent No. 74754/1980, 17 June 1980.

17. Marioni, A. Sistemi di Isplamento Sismico Innovetivi Prodotti dalla Societa ALGA. In Moderni Sistemi e Tecnologie Antisismici. Una Guida per il Progettista; 21mo Secolo: Milano, Italy, 2008.

18. Dobrescu, C.F. Analysis of Dynamic Earth Stiffness depending on Structural Parameters in the Process of Vibration Compaction. Rom. J. Acoust. Vib. 2019, 16, 174-177.

19. Dobrescu, C.F. Dynamic Response of the Newton Voigt-Kelvin Modelled Linear Viscoelastic Systems at Harmonic Actions. Symmetry 2020, 12, 1571. [CrossRef]

20. Dobrescu, C.F. Evaluation of the dynamic compaction effect with vibrating rollers based on the rheological behaviour of soil. Acta Tech. Napoc. 2020, 63, 191-196.

21. Spânu, G.; Drăgan, N. Gradul de Izolare a Reazemelor Elastomerice. Modelul Voigt-Kelvin. In Proceedings of the Buletinul celui de-al XXIII-lea Simpozion Naţional de Utilaje Pentru Construcţii SINUC 2017 (CD), Universitatea Tehnică de Construcţii, Bucureşti, Romania, 3 November 2017.

22. Spânu, G.; Drăgan, N. Analiza Dinamică a Sistemelor 1DOF cu Reazeme Elastomerice. Modelul reologic Maxwell. In Proceedings of the Buletinul Celui de-al XXIII-lea Simpozion Naţional de Utilaje Pentru Construcţii SINUC 2017 (CD), Universitatea Tehnică de Construcţii, Bucureşti, Romania, 3 November 2017.

23. Mortelli, A.; Sannino, U.; Parducii, A.; Braga, F. Moderni Sistemi e Tecnologie Antisismici; 21/mo Secolo: Milan, Italy, 2008.

24. Naeim, F.; Kelly, J. Design of Seismicisolated Structures; John Wiley \& Sons, Inc.: Hoboken, NJ, USA, 1999.

25. Bratu, P. Hysteretic Loops in Correlation with the Maximum Dissipated Energy for Linear Dynamic Systems. Symmetry 2019, 11, 315. [CrossRef] 